Please send trade news information and illustrations to Arveen Bajaj at the $B D J$, Nature Publishing Group, The Macmillan Building, 4-6 Crinan Street, London N1 9XW.

Trade news is provided as a service to readers using text and images from the manufacturer, supplier or distributor and does not imply endorsement by the BDJ. Normal and prudent research should be exercised before purchase or use of any product mentioned.

\section{First multifunction digital X-ray}

DMDS have launched the very first multifunction digital X-ray on the UK market the brand new ADX 4000.

A convenient three-in-one machine, the ADX 4000 combines an X-ray source, digital radiography sensor and computer processor in one completely portable and wireless handheld unit. This makes the equipment incredibly versatile and it may easily be moved from one surgery to another if required.

The ADX 4000 has an image storage facility of 300 images and emits low radiation whilst maintaining extremely high quality images all without the inconvenience of processing films and the waiting around that goes with

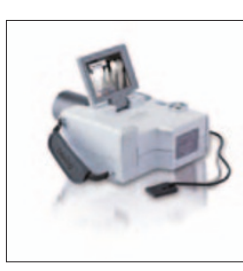

manual X-rays. For fur-
ther information please
contact DMDS on
01227780009 or visit
www.quickwhite.info.
Reader response
number 52

\section{New luxation kit}

The widespread use of elevators to reduce trauma during extraction has led DENTSPLY Ash ${ }^{\circledR}$ Instruments to introduce a range of luxation instruments.

The tips of $\mathrm{Ash}^{\circledR}$ luxation instruments are finely tapered and offer a combination of the characteristics of a periotome and an elevator. The sharp tips allow for more efficient cutting of the periodontal ligament and the tapering shaft offers controlled expansion of the bony socket.

The Ash $^{\circledR}$ Luxation Kit comprises four luxation instruments to help improve extraction procedures: a straight blade and a curved blade in two different widths, a Ceramicolor ${ }^{\circledR}$ Heidebrink apical elevator, a sharpening stone and a honing rod to keep the instru-

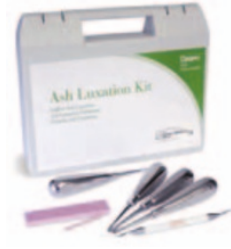
ments in perfect condition. For more information please contact DENTSPLY on 01932 837297.

Reader response number $\mathbf{5 3}$

\title{
UltraOzon
}

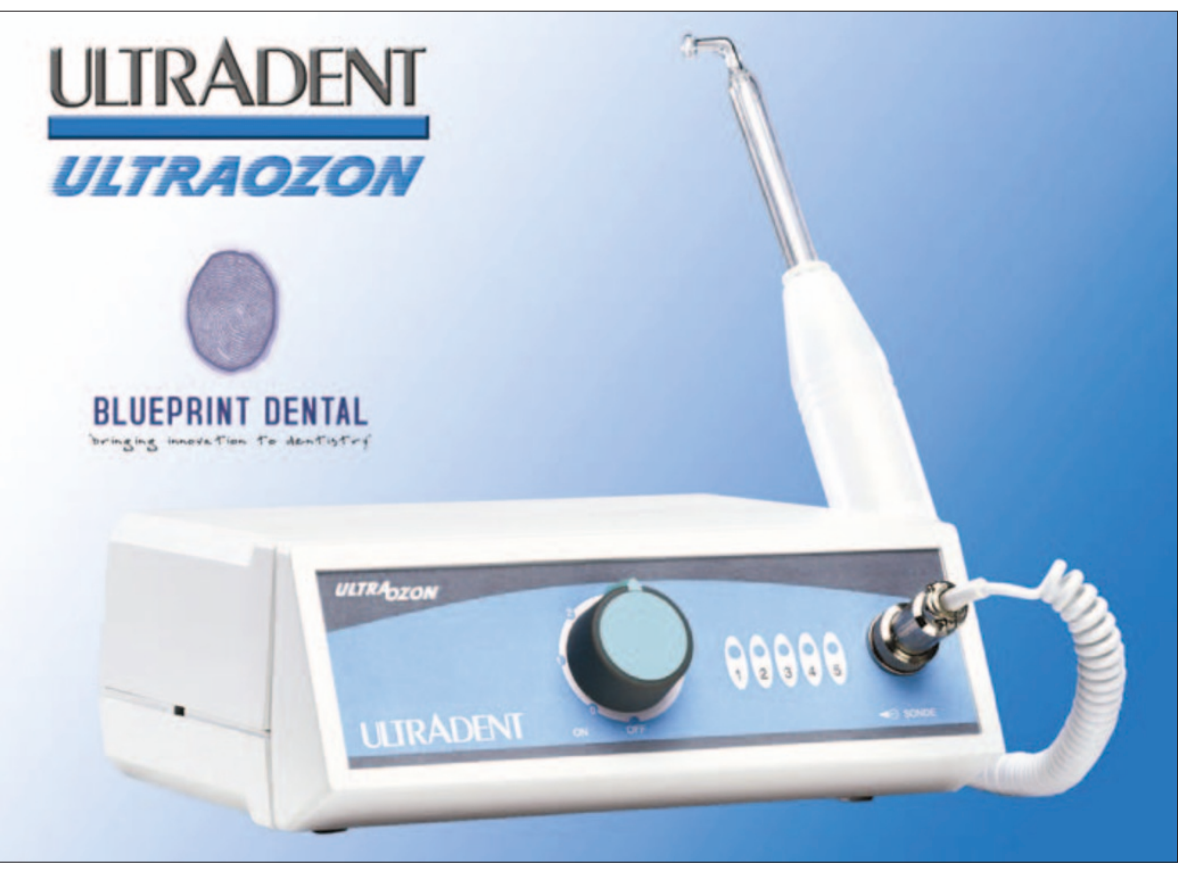

Blueprint Dental has introduced an alternative ozone therapy unit to the market - the UltraOzon from Ultradent. UltraOzon ozone is produced by an electromagnetic field directly at the point of contact, where free oxygen atoms are produced at a concentration of approximately $525 \mathrm{ppm}$. Application is therefore fast and safe, and the therapy is noninvasive and pain-free with no side-effects. The very specific ozone production from the UltraOzon allows for a broad spectrum of possible indications in three main areas: inflammation treatment and prophylaxis, wound treatment and caries treatment. A variety of treatment probes are available, including a new KP-probe especially for endodontic and periodontic treatments where the injection of ozone directly into the root canal or pocket is possible. The UltraOzon will retail for $£ 4,250$ excluding VAT. For more information contact Blueprint Dental on 08704329786 or email info@blueprintdental.co.uk. Reader response number 50

\section{D digital radiography}

Finally, the dream of three-dimensional images for diagnostic examination has become a reality with 3D Accuitomo. Only available in the UK from The Dental Imaging Company, 3D Accuitomo has three big advantages compared to conventional medical CT: high resolution, low X-ray radiation, and small size - it requires only $2 \mathrm{~m} \times 1.8 \mathrm{~m}$ of space.With excellent sensitivity, high resolution and a wide dynamic range, as well as expressive imaging tone, 3D Accuitomo creates brilliant images of both soft and hard tissue areas. Diagnostic images that are difficult to observe with conventional twodimensional radiographs, such as implants, apical abscesses, TMJ disorder and impacted teeth are therefore possible. The radiographic area can be freely selected and positioning and exposure release is the same as a dental panoramic X-ray, and just as patient-friendly. For more information contact The Dental Imaging Company on 07050652250 or email sales@thedentalimagingcompany.co.uk.

Reader response

number 51

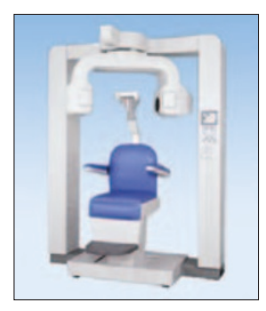




\section{Safety first in endodontics}

The Kerr M4 Safety Handpiece is all about delivering the very best results time after time. Utilising ordinary ISO endodontic hand instruments, the M4 oscillates at 60 degrees allowing the instrument to glide and centre itself along the walls of the root canal. It mimics the hand movement most practitioners use in endodontic therapy, ensuring safety throughout the procedure.

The M4's 4:1 gear ratio can function at full speed without undue torquing, allowing a recommended speed of approximately 5,000-6,000 rpm. Fully autoclaveable and with an integrated water coolant system, the M4 also incorporates a push-button chuck, making switching instruments during procedures quick and simple and saving precious time. As almost any 'hand' endodontic instrument will fit in the M4's chuck, there is also no need to replace your existing inventory. However, it is ideal for use with Kerr's K-Flex files, one of the most reliable files on the market.

For the ultimate in speed and efficiency that simplifies even the toughest endodontic challenges, including sclerosed canals, consider the M4 Safety Handpiece today.

For further information please contact KerrHawe on 01733892292.

Reader response number 54

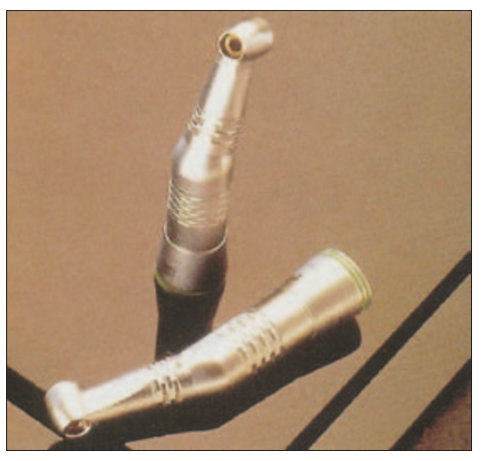




\section{Smart endodontic motor}

The $\mathrm{X}$-Smart ${ }^{\mathrm{TM}}$ endodontic motor introductory kit is the perfect choice for clinicians looking for a rotary endodontic system. The smart and simple motor is available in a kit with NiTi ProTaper ${ }^{\circledR}$ rotary files, two contra angles and several other accessories to get you started.

The motor has a lightweight handpiece with a small head, making the treatment site highly visible. The motor is driven by a button on the handpiece, eliminating the need for a foot pedal and making the unit highly portable - useful for a multi-surgery setup. In addition the motor has a small footprint, the control panel is simple and there is a large LCD screen, making it easy to operate. There are also three auto-reverse modes that reduce the risk of file separation.

For more information contact DENTSPLY on 01932837313 or email kathryn.norris@dentsply-gb.com. Reader response number 55

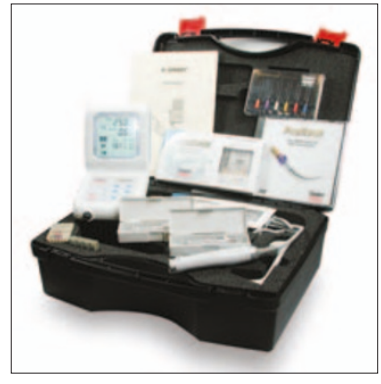

\section{Risk free cores}

Premier Compcore from Myerson is a dual-cure, fluoride releasing, radiopaque core build-up material. The patented hyperbranched molecular structure of Compcore ensures a dense crosslinking of the composite monomers to ensure complete curing all the way through the material. This significantly reduces shrinkage and contraction stresses that would inevitably lead to microleakage, resulting in secondary caries. The low solubility ensures a perfect marginal seal and the high compressive and tensile strengths provide a solid foundation for final restorations.

Compcore is supplied in a convenient and compact automix syringe with both small tips and right-angled dispensing tips, allowing fast and absolutely precise placement. There are three shades to choose from; blue, A3 and white. Compcore flows easily, stacks without slumping and to make life even easier it preps just like dentine. For more information and details of a risk free trial call Myerson on 02088639044.

Reader response number 57

\section{RC-Prep ${ }^{\mathrm{TM}}$ now CE certified}

Over 40 years of clinical use and numerous publications demonstrate the clinical efficacy of RC-Prep ${ }^{\mathrm{TM}}$ for chemo-mechanical preparation of root canals. RC-Prep ${ }^{\mathrm{TM}}$ 's unique formulation of glycol, urea peroxide and EDTA in a special water-soluble base has made it the clinician's choice for helping remove calcifications while whitening, deodorising and lubricating the canal to permit more efficient instrumentation.

Now Premier Dental's quality management system is successfully registered with ISO 9001:2000 and IS013845:2003, together with the CE Mark for RC-Prep ${ }^{\mathrm{TM}}$. Whether practitioners prefer finger or engine-driven instruments, RC-Prep ${ }^{\mathrm{TM}}$ allows reamers and files to move easily without binding and is also excellent for use with apex locators as it permits consistently reliable readings. Now available from your regular dental supplier, buy two packs of $2 \times 9 \mathrm{~g}$ syringes and receive a third pack FREE! For further information please contact Myerson on 02088639044.

Reader response number 56 


\section{Disinfection on demand}

To achieve long-term restorative success of endodontic treatment it is vital to disinfect root canals. The P.A.D (Photo-Activated Disinfection) system from Denfotex improves long-term restorative success by eliminating all species of oral bacteria on demand, giving consistent results and rapid resolution of periapical lesions.

In a simple and quick procedure, P.A.D. solution is syringed into the canal(s) and activated by a high technology cool light emitted through a specially designed handpiece tip introduced into the canal. The aqueous P.A.D. solution effectively wets the canal wall and selectively targets and locks on to all bacterial species. When exposed to the P.A.D. light, $99.99 \%$ of bacteria are killed in seconds.

P.A.D. is a quick and effective means of disinfecting root canals, making it particularly useful in endodontics. The practitioner can also be reassured that should the P.A.D. solution penetrate the apex, neither it nor the P.A.D. process will cause an adverse reaction so disinfection may be performed immediately.

For further information please contact Denfotex on 01383411555 or visit www.denfotex.com. Reader response number 58

\section{Silver restorative}

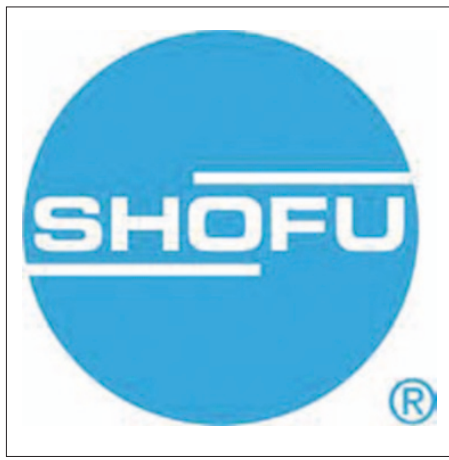

Hi Dense silver reinforced glass ionomer restorative from Shofu is the perfect core build up material. Hi Dense packs like amalgam making it easy to manipulate, and the high compressive strength from the spherical silver tin alloy within the specially formulated glass ionomer allows it to withstand the high forces that may be put upon the material. Being radiopaque, Hi Dense is also easy to detect on your radiographs.

This well proven mercury-free silver reinforced glass ionomer is available in a capsule that does not require a capsule press; alternatively, you may opt for the hand mix version. Both versions produce a putty-like consistency, making it the perfect choice for core build ups, as well as other applications including use as a base underneath composite or amalgam restorations, and on root abutments for locating overdentures.

For further information please contact Shofu on 01892870800.

Reader response number 59

\section{Cutting costs not corners}

Whatever your endodontic requirements, be they manual or mechanical endodontic instruments, reamers or gp points, you will find a huge selection of brand leading products in Dental Sky's portfolio. Dental Sky also produce a superb selection of high quality own branded products, at extremely competitive prices. Examples include 200 R \& S paper points for as little as €3.50 a box (plus VAT) and DentoClic gates glidden drills at just $€ 7.90$ for a box of six instruments.

Another bargain is the Endo Micro Plus box. This endodontic aluminium box contains 24 holes, clean grip for instrument cleaning and two plastic pots for gp or paper points at only $£ 21.90$ each (plus VAT).

Dental Sky guarantees that you will not pay more for the same product bought in the UK or they will refund the difference. For further information please contact Dental Sky on 08002944700. Reader response number 60

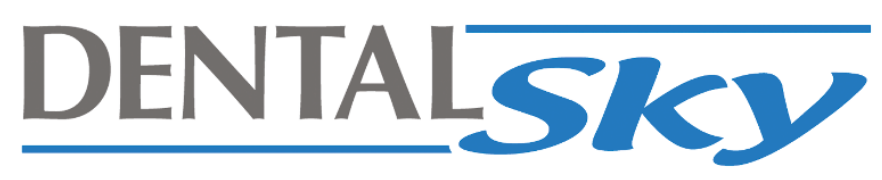

\section{AH PlusTM Sealer}

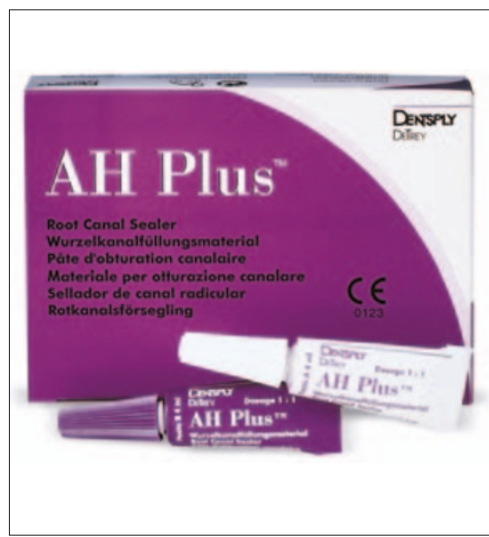

AH Plus is an epoxide-amine resin pulp canal sealer that is an ideal choice where aesthetic demands are high. The material has a perfect working consistency and because it is slightly thixotropic, it flows better under pressure. AH Plus is heat tolerant and the setting reaction is not adversely affected during thermoplastic obturation, making it very well suited for warm compaction techniques.

The small filter size and film thickness combined with the flow characteristics of AH Plus allow for good adaptation to the entire root canal system. Because the material has good dimensional stability, low solubility and adheres to dentine, it is possible to produce an excellent seal. AH Plus is also extremely radiopaque, so penetration of the material into any accessory anatomy is clearly visible on radiographs, even when there is a thin film thickness. All these features make AH Plus an excellent choice for use with a variety of obturation techniques.

For more information contact DENTSPLY on 01932837313 or email kathryn.norris@dentsplygb.com.

Reader response number 61 